\title{
Pilot Study on Bread Wheat Production Efficiency of the Small Scale Farmers in Hetosa District of Arsi Zone
}

\author{
Anbessie Debebe Abboye Almaz Admasu Terefie* \\ Kulumsa Agricultural Research Center, Ethiopian Institute of Agricultural Research, \\ P. O. Box 489, Asella, Ethiopia
}

\begin{abstract}
*Corresponding Author: Almaz Admasu Terefie ${ }^{1}$ Department of Agronomy Research Program, Kulumsa Agricultural Research Center, Ethiopian Institute of Agricultural Research, P. O. Box 489, Asella, Ethiopia.

Abstract

This pilot study investigates the production efficiency of the small and medium-scale farmers in bread wheat based farming system of Hetosa district in Arsi Zone of Oromiya regional state in the central part of Ethiopia. The analysis is based on the cross sectional data collected from 26 farmers selected using simple random sampling method in 2017. The wheat production efficiencies were estimated using stochastic frontier production function in which inefficiency is assumed as a function of different productivity factors. The general low level of efficiency of farmers is an indication of high potential that exists to improve the productivity of farmers through improving the efficiency level of those less efficient farmers. More farmers operate at lower efficiency level for wheat relative to barley. Whereas the opposite is true for higher efficiency level indicating that more farmers' approached the frontier for barley production relative to wheat production; possibly due to the traditional nature of the barley technologies. In the analysis of causes of inefficiencies, it has been found that average education level and proximity to development center are important factors that affect the production efficiency level positively. Total area managed by farmer is also observed to have a similar impact on the overall efficiency level of the farmers in the study area. As a result, to raise the level of bread wheat productivity in the study area, intensive efforts have to be made for the strengthening of the infrastructure, development of the social services, and the integration of agricultural activities.
\end{abstract}

Keywords: Bread Wheat, Extension Contact Farms Size, Household Size, Production Efficiency, Small-Scale Farmers, Usage of Technologies,

DOI: $10.7176 / \mathrm{JBAH} / 10-3-03$

Publication date: February $29^{\text {th }} 2020$

\section{INTRODUCTION}

Bread wheat (Triticum aestivum L.) has originated from natural hybrids of three diploid wild progenitors native to the Middle East. These are T. monococcum, T. tauschii and Aegilops speltoides It is an annual cool season cereal crop but it can grow in a wide range of environments around the world. Its production is highly concentrated between the latitudes of $30 \mathrm{o}$ and $60 \mathrm{o} \mathrm{N}$, and $27 \mathrm{o}$ to $40 \mathrm{o} \mathrm{S}$ (Hailu, 1991), and within the temperature range of $3 \mathrm{oC}$ to $32 \mathrm{o} \mathrm{C}$. Bread wheat is an important cool weather crop grown predominantly in the Ethiopian highlands at optimum altitude ranging from 1000 to 2300 meters above sea level. Wheat occupies large area $(0.8$ million hectares) of land and produces large amount of grain every year. It furnishes the flour to make bread and injera that is consumed throughout the country. Wheat production like that of teff receives large amount of inorganic fertilizers and herbicides; to some extent fungicides against rust diseases (Abate, 1995).

In Ethiopia, wheat is an introduced crop, although its time of introduction is immemorial (Hailu, 1991). This author also mentioned that, this crop is one of Ethiopian's staple foods and the main sources of calorie in the major producing regions; and it is grown between latitudes of $6 \mathrm{o}$ to $16 \mathrm{oN}$, and $35 \mathrm{o}$ to $42 \mathrm{oE}$, with altitudes ranging from 1500 to 2800 masl. It covers more than one million hectares accounting for $13 \%$ of nearly 8 million hectares of land allocated to all cereals. Bread wheat stands fourth in total national grain production and third in yield per hectare (CSA, 2002). Bread wheat is believed to be a relatively recent introduction to Ethiopia (Hailu, 1991); it exhibits wider adaptation and higher yield potential than durum wheat (Amsal, 2001). Drought prone environments particularly semi-arid environments, which cover $50 \%$ of the country's arable land area, have been one of the principal constraints for wheat production in rain fed areas.

The wheat production of Ethiopia is characterized by its deprived performance, while the population of the country, which to a large extent depends on the small farms size with low crop production efficiency, is growing at faster rate. In other words wheat production efficiency is not in a circumstance to preserve consistency with the rapid population growth that has been feeding. Development efforts, on the other hand, are ongoing together with research and extension, to overwhelm the production efficiency problem of the sector. This necessitates looking for a means to increase the wheat production efficiency of the small and medium farmers, the dominant producers, which can be either by introducing new technologies or improving the productivity of the farmers.

In view of the increasing population, further advances are required in agricultural research with a view to achieve increased production and improved production efficiency. 
In this pilot study of wheat production efficiency the average amount of the product result is a good indicator of the production efficiency that could be achieved from capable farmers that engaged in concerned agricultural farming activities. Researchers up to now have not been shown to carry out any studies in Arsi area reflecting the effect of farms size and bread wheat production efficiency at district or zonal level.

With the above facts bearing in mind, it was conducted such a minor study on bread wheat crop production efficiency and hence, the purpose of this study was to evaluate the production efficiency of the small and medium-scale farms size in selected peasant kebeles at Hetosa district of Arsi zone in central part of Ethiopia. This study was conducted based on the primary and secondary data through in depth interview with about 26 selected model farmers and visual and hidden dissection with the Hetosa District Agricultural Development Office agronomists and extension workers.

\subsection{Statement of the Problem}

In Ethiopia bread wheat production efficiency is not in a situation to keep regularity with the rapid population growth that has been feeding. Development effort, however, is continuing including both research and extension, to overcome the problem low production efficiency of the sector. Some of the strategies followed-package program-are of all-purpose category that may not automatically target a particular of the country. Since the foundation of the Chilalo Agricultural Development Unit (CADU) in the late 1960's significant agricultural development efforts have been made in Arsi. Several production technologies, for various crops have been released from research centers. Attempts have also been made to disseminate these technologies particularly to farmers since then.

It is evident that, Hetosa district is one of those areas where emphasis has been given to disseminate the generated technologies particularly for Wheat. This area has been also well known to use more modern agricultural inputs compared to other areas. Theoretically, introducing modern agricultural technologies can raise Bread Wheat production efficiency. However, according to Tarkamani Hardakar 1996-cited in (Mohamed 1999) in areas where there is inefficiency, trying to introduce new technology may not have the projected impact if accessible knowledge is not economically utilized. In Ethiopia, many studies in different regions have indicated the existence of production efficiency differentials among farmers. If new technologies are generated and diffused continuously, farmers are in disequilibrium (Mohamed 1999).

This may hold true for many other areas not covered by the studies, especially areas such as Hetosa district, where there is research and extension involvement. In such areas, change in the level of production efficiency is more distinct than in those areas with less involvement. Thus despite higher level of technological adoption, there is still low average production efficiency amongst farmers. This may show the continuation of unproductive utilization of technologies adopted.

Therefore, identifying factors that make a contribution to unproductive and tackling them to raise production efficiency might be more important than trying only to introduce technologies. In fact such a study is of prime importance because it helps to avoid redundancy of efforts and wastage of development resources. Moreover, it enables the identification of major areas of involvement where intensive efforts have to make to raise the agricultural production and production efficiency of the small scale-oriented farms. With the above facts bearing in mind, it was intended to conduct this minor assessment study project and the intention of this study was to evaluate the bread wheat crop production efficiency and to make an economic evaluation for the small and medium-scale farmer's production efficiency in selected farmer kebeles of Hetosa district. It assesses the concept of productivity, its past evolution and present levels of the medium-scale farmer's productivity in its consequent sections.

\subsection{Significance of the Study}

Production efficiency is a very important factor of economic growth specifically in developing agricultural economies, where resources are insufficient and opportunities for developing and adopting better technologies are declining. An empirical study of farms specific production efficiency helps to determine how much it is possible to raise output with the existing technology; and eventually whether it is possible to raise production efficiency by improving efficiency, a usually disused source of production efficiency growth, with the given technology or to develop new technologies in order to raise the bread wheat production efficiency levels.

The appropriate utilization of the obtainable technologies will make fruitful to all of the development efforts. Thus improving the medium-scale farmers' production efficiency level could provide an alternative source of growth. In older to improve the production efficiency level of the farmer, one should have to know, in advance that, the existence of variations in production efficiency levels amongst farmers. Moreover, those factors contributing to the inadequacy differentials amongst the farmers have been recognizing in order to make and plan improved policy for intervention.

If policy makers know why some farmers are better managers-why there are income growth inequalities than the others are, they might have firmer ground for selecting amongst a range of programs. Finally, it can be expected 
that the isolation of the causes with unproductively will permit the formulation of the exact remedial or corrective alternatives which can used for an improvement of the medium-scale farmers. Therefore, it is worth noting that the finding of this pilot study will help both policy makers and development workers to focus on those factors, which has identified as to be as the principal cases of unproductively. Moreover, the outcome of this study can serve as a facilitator for other similar and detailed studies in the region. It has been also anticipated that the zonal and regional planning bodies, researchers and policy makers can possibly use the finding of this pilot study as an input in their future works.

\subsection{Objectives of the Study}

The major objective of this study was to evaluate the level of the bread wheat production efficiency of the small and medium-scale farmers with 1-25 hectare farms size in Hetosa district.

The specific objectives are:

- To evaluate the relationship between farms size and use of improved agricultural technologies and inputs.

- To evaluate the relationship between the educations level of farmers and total farms size.

- To evaluate and compare the agricultural productivity of the study area with the district, zonal regional, national and worldwide averages

\subsection{Scope of the Study}

The vital indicators used in this pilot study will be only the actual small and medium-scale farmers with 1-25 hectare farms size. Other off-farm activities and accessibility of credit that could raise the small scale's entitlement conditions were not studied.

\subsection{Limitation of the Study}

The study has some limitations that originate mostly from lack of enough time, budget and facilities. In the first place, the study excludes the agricultural commercialization competent of the farm. Therefore, future research needs to consider this important component of farming system. Secondly, the study has used a cross-sectional data, which only reflects farmers' circumferences in a given year.

This has been affected by the specific climate of the year as agriculture in the country in general, and in the study area in particular, is dependent on weather. Moreover, the results of cross-sectional data do not show the change over time, which may be important for a follow up development strategy. Thus, it may be important for future research to measure the efficiency of farmers' overtime.

The initial intention of this study was to find out historical data - as far back as possible particularly on the progress of the major variables. However, difficulties soon become apparent because of not at there any historical perspective information or any kind of the necessary compiled data. Therefore, visible observations had to be limited to some consecutive recent years as well as of the late discrete years. Even then, some of the necessary information surveyed had incomplete or inconsistent data and were excluded. Thus, out of 65 small scale-oriented farmers observed, only 60 farmers have been retained. The study was, thus, very much conditioned by the type of data generated during the observation. One of the major limitations of these data is the lack of time-series observations.

\section{MATERIALS AND METHODS}

The bread wheat production efficiency level study has been conducted out in four farmer kebeles of Hetosa district; namely Oda Jila, Gonde Finchama, Hatte Handode and Shaki Sherera. The rationale for selecting these kebeles was their production potential among the 23 kebeles in the district. The four most productive kebeles were chosen using simple random sampling method. As the most important issue of this study is to see the productivity situation of the households in the area that has reported to be economically efficient and food guaranteed as well as most productive Kebeles in the district has identified by the district Ministry of Agriculture (MoA) officials. For this study there were limitations of time to collect, analyze and write the report. Furthermore, it was not so easy, as such to enter the collected large data into the computer and be ready for analysis within the given time frame. Apart from this there was a financial constraint to collect and manage the large data set. Considering all the circumstances, 26 farmers were sampled and interviewed for this pilot study.

\subsection{Description of the Study Area}

Hetosa is an administrative district of Arsi Zone in central Ethiopia. It is to be found at some about $110 \mathrm{~km}$ east of the capital Addis Ababa. The district has situated on an estimated total area of 1141.01 square kilometers and it is divided in to 28 administrative unites called kebeles out of which 23 are peasant associations (PAs).

The total projected population of Hetosa district for July 1997 was 187,556 and it was composed of 87 percent rural and 13 percent urban population. In the late 1997 Hetosa district had a crude population density of 164 persons per square kilometer (Getachew 2001:7). Gently sloping plains, hills and gradually rising slops of 
land characterize the topography of Hetosa district. Its altitude ranges from 1500 to 4170 meters above sea level. The mean annual rainfall of the area ranges from 400 to $1600 \mathrm{~mm}$.

According to the common Ethiopian agro-climate classifications, the district divided in to three climatic zones; namely, 32 percent Dega (wet-cool), 48 percent weina Dega (wet-warm) \& 20 percent kola (warm). It has a bimodal rainfall type; the first and smaller rains (belg) peaking in April, and the second in midSeptember. All the three climatic zones are conducive for crop and livestock production. The major soil orders in this district are Andisol and vertisols covering 35 and 45 percent of the total area, respectively.

Hetosa district has a mixed crop-livestock farming system. Farmers produce both crops and livestock while the latter is no good with increasing demand farmland as a result increased population growth. Crops grown in this district are cereals, pulses, and some oil seeds. The dominant crops grown are cereals, particularly wheat followed by barley.

However, other crops such as sorghum, maize, faba beans, soya bean and field peas, also produced in smaller amounts. The livestock population of the district has s estimated to be 21,397 head of animals excluding poultry of which 126,490 heads are cattle, 65,205 heads are sheep and goats and 22,702 heads are horse's mules and donkeys. The average livestock densities in the district were 187 heads of animals per square kilometer in 1900 (Getachew 2001:8)

According to the study results of (Yesuf, A. and Duga, D. 2000:97) the soil physico-chemical characteristics in the study area are summarized hereunder:

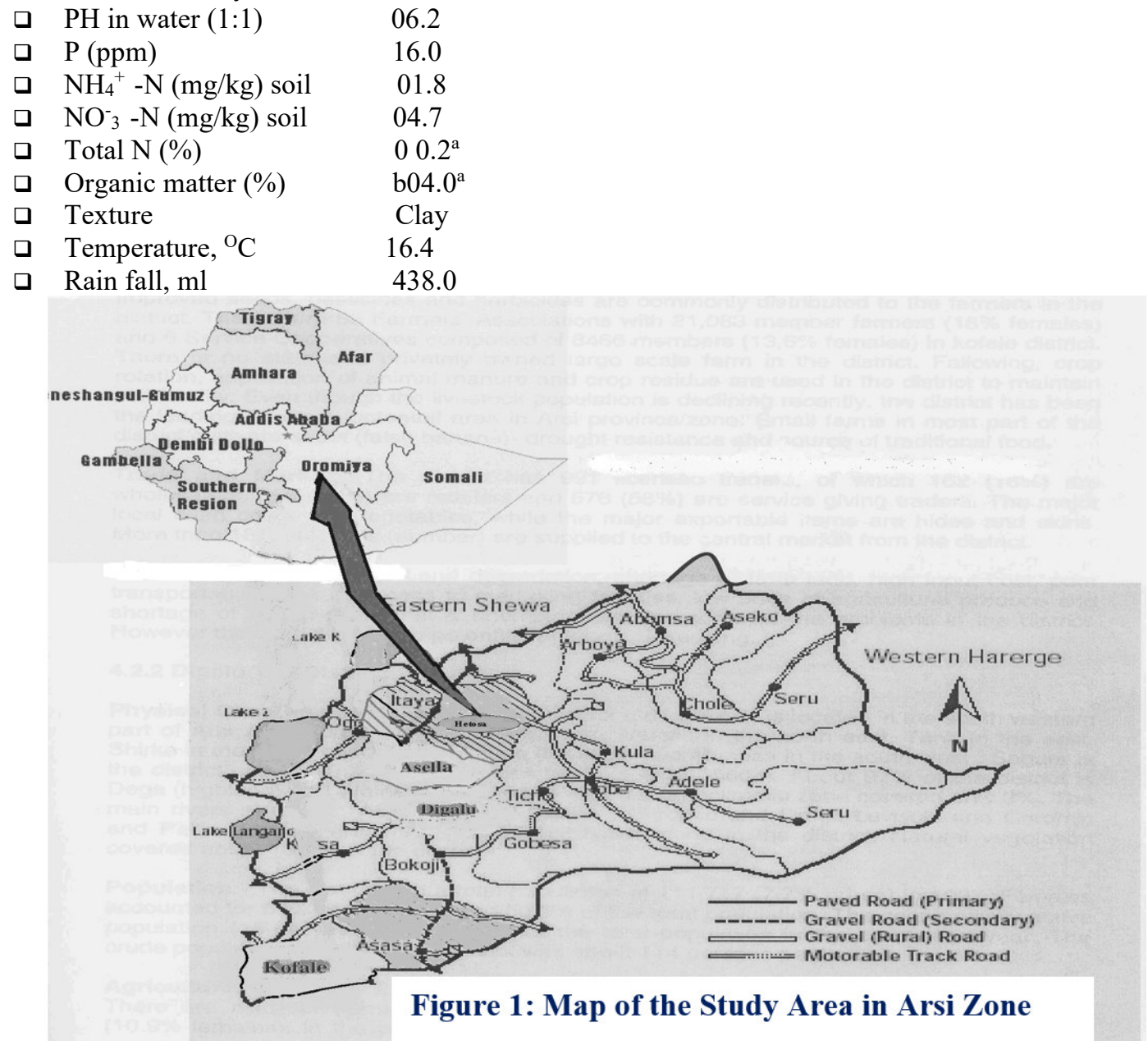

The data used for this pilot study have gathered from primary and secondary sources. The primary data have gathered through official in-depth interview with selected model farmers and visual desiccation with the Hetosa district Agronomists and Extension Development Agents. Unofficial discussion was also made with all the three groups to get their broader view before and after observative interviews. The secondary data was obtained from recently worked literatures which are documented in the Library of Kulumsa Agricultural

a 1995 Data 
Research Center.

\subsection{Methods of Data Collection}

The data collection methods engaged to gather from primary and secondary sources are described in this subsection.

Primary data sources: The methods employed to collect the primary data were:

- In-depth official interview with selected model farmers and visual desiccation as well as informal telephone communications with the Hetosa district MoA Agronomists and Extension Development Agents.

- Personal hidden and visual observations during the interview including unofficial discussion and telephone communications before and after observative interviews.

a) In-depth official interview: Official in-depth interviews were held with some groups of resident farmers at the study area. The initial intentions were to make some kinds of visual interview with about 77 selected farmers and as well as to make a visual discussion and a hidden telephone communication with Hetosa District Agricultural Development Office (HDADO) experts, resident development agents and some of randomly selected group of model farmers. However, difficulties soon become visible which were originated from lack of enough time, budget, vehicle and other means of communication facilities. However incidentally too, an official interview and visual desiccation with the HDADO agronomists and with merely about 26 selected representative farmers were made at different days.

b) Personal hidden and visual observation as well as telephone communications:

It has been made some very valuable observations during the interview with all the three groups to get their broader view before and after the interviews. In respect to the existing history of the study area, unofficial debates have undertaken with groups of 5-10 farmers for over 0:30-1:00 hour certainly based on the sociopolitical situation and as a result which are concluded as; land-use adjustments were linked to changes in government, as this has defined structural changes in farmlands use. After a brief discussion on the specific issue, some local parameters have been defined and the arrangement has also constructed by looking at these parameters over time. Once the arrangement was completed, a discussion raised, by analyzing each parameter in each time period.

II. Secondary data sources: Appropriate secondary data was gathered from the respected sources of the above mentioned. These data was used to examine the bread wheat productive efficiency of the medium-scale farmers in the study area. The analyses were classified in to four parts. The first part illustrates the relationships between farms size and use of improved agricultural inputs.

The second part analyzes the household-heads distribution by amount of fertilizer used for production. The third part reviews the distribution of households by the number of Extension Contacts (EC) in the late 2001s. The fourth part will compare and contrasts the farms size, households size and average grain productivity level for wheat with average productivity level all with based on the secondary data of the national, regional, zonal and district levels. 


\subsection{Sampling Method and Design of the Studded Area}

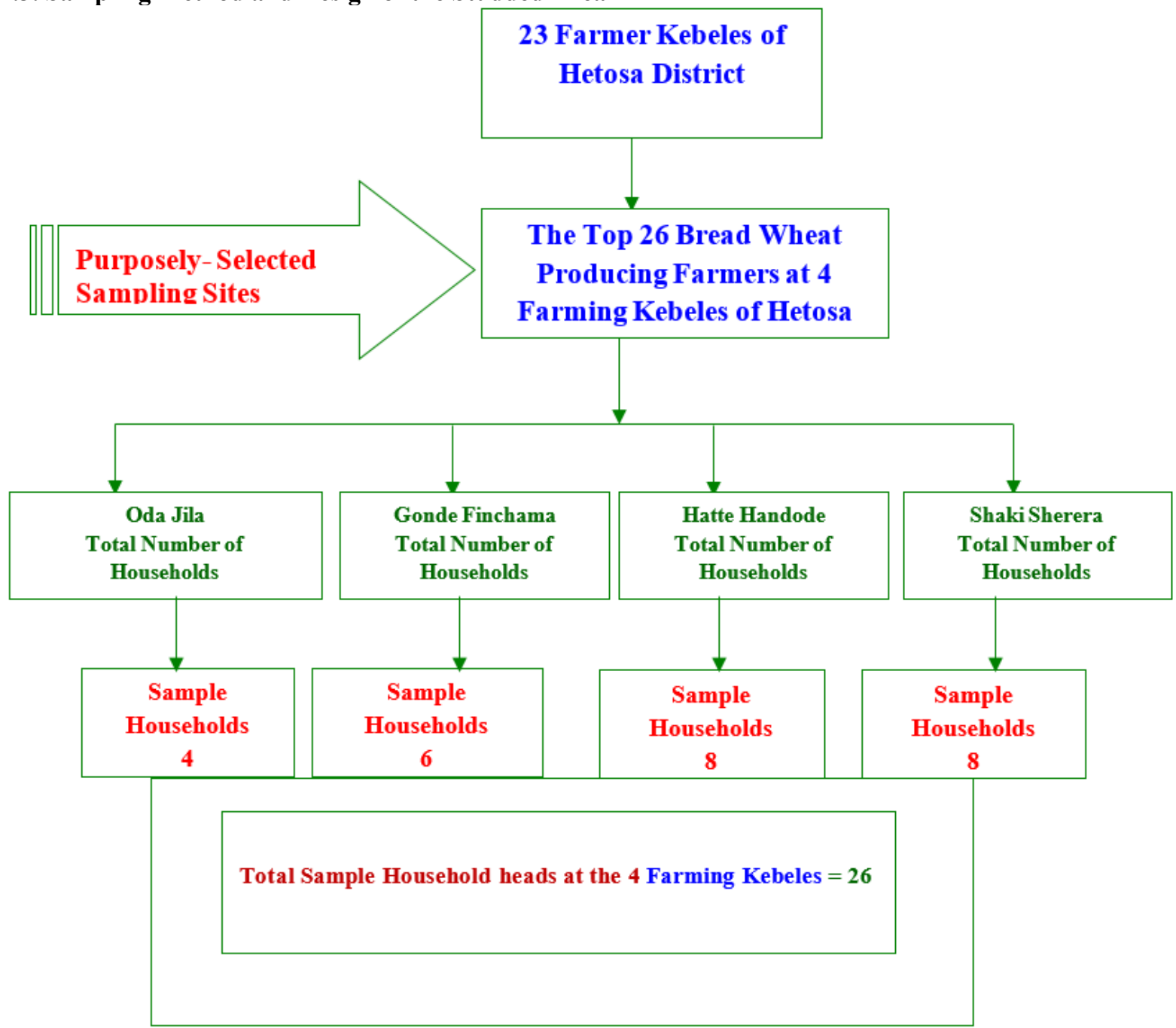

This sampling design is an adjusted operational sampling design to be applied depending on the purposely created prescription at the proportional percent of the total household heads.

\subsection{The Field Survey Findings and Data Interpretations}

The data gathered through interview was coded in and analyzed using simple statistical packages. The data gathered through elite interview, discussion with informants and the in-depth observations were used in support to the information obtained from the interview. The information acquired from secondary sources was used all over the analysis.

The collected data were entered in to the computer and analyzed using excel spread sheet. Average, frequency, mean, percentage and rank of the productive efficiency were used. The findings were presented using tables, graphs, and figures. Finally the results were then interpreted, discussed and compared with relevant literatures.

\subsection{Data Analysis and Discussion}

I. The Primary Data Analysis: Based on the collected primary data it has been tried to investigate the bread wheat productive efficiency of the medium-scale farmers in the study area. The analysis has been organized under three parts. The first part describes the personal, household, and farm characteristics that have an effect on productivity situations of household-oriented farmers. The second part reviews the yield productive efficiency of the medium-scale farmers' in the study area which are with 1-2.5 hectare farms size and it investigates the degree of local inequality in distribution of food amongst farmhouse holds. The third part investigates the relationship between the selected personal, household and farm characteristics.

Personal, Family and Farm Characteristics: This part describes the major personal, Family and farm characteristics. These factors are illustrated below.

Personal Characteristics: Out of the 26 household-heads, about 84.6 percent were male and about 15.4 percent 
were female. About 42.3 percent of the average age household-heads were found in the most actively working individuals' age category of 32-45 years. Table 1 presents the distribution of household-heads by age.

Family size characteristics: The average Family size in the study area has shown to be approximately 6.9 people per households. This was higher than the national averages, which were 7 in 2001 (Getachew 2001:45). But any way, about 20 family members were registered in one household.

Farming was the major source of living for households in the study area. This has its own pressure on the degree of vulnerability of households to their farms productivity because of the unfavorable climatic and other critical situations that hinder the right achievements in their production efficiency.

Farms characteristic: The most important farms characteristic described in this part of the study are farms size, wheat production.

Farms Size: Under circumstances where the economic capacity of farmers is very low to afford using improved agricultural technologies that increase productivity per unit of land.

Farms size is the major factor that determines production amount that the farmers can produce in a given time. Table 1 shows the distribution of households by farms size.

Table 2: Distribution of household-heads by Farms size Category. $(n=26)$

\begin{tabular}{|llll|}
\hline & \multicolumn{3}{c|}{ Household-heads } \\
\hline Farms size in ha & Number & Percent & Productive efficiency rank \\
\hline $\mathbf{1 . 0}-\mathbf{2 . 5}$ & 15 & 57.69 & 1 \\
\hline $\mathbf{3 . 0}-\mathbf{4 . 5}$ & 6 & 23.08 & 2 \\
\hline $\mathbf{5 . 0}-\mathbf{7 . 0}$ & 3 & 11.54 & 3 \\
\hline $\mathbf{2 ~ 0}-\mathbf{2} \mathbf{4}$ & 2 & 7.69 & 4 \\
\hline Total & 26 & 100 & \\
\hline
\end{tabular}

Source: computed from primary data of (Anbessie survey data 2015)

The average farm size amongst the household-heads was 4.1 hectares and this figure was above average sizes for the national figure is1.02 hectares (Anbessie 2015). Where land is marginal and no fertilizer is used, households farming less than 1 hectare can be classified as chronically unproductive. (Getachew 2001:46). In despite of the fact that the use of fertilizer and other agricultural inputs was not uncommon in the study area, this argument might hold true for 19.2 percent of the households that have only 1 hectare of land if they cannot afford to use fertilizer and other improved farm inputs.

About 2 percent of the sample household heads raised their farmland using different techniques. These techniques were renting in for a certain time of a year or more, sharecropping in, and reclaiming marginal lands for farming. That is why the farm size of 2 farmers is exaggerated up to 20 and 24 hectares. The household heads were also asked whether their farmland was enough to feed their family throughout the year. About 48 percent of the household-heads said that their farms size was enough to supply their family throughout the year while the rest 52 percent of the household heads said their farm size was not enough.

Crop Production: According to the collected primary data the major crops grown in the study area were wheat and fababean. Barley, maize, sorghum, soya bean were also produced in smaller amount. The main productive crops in the study area were wheat and fababean. When households rank their main crops in order of their productive importance, wheat, fababean, maize and barley were the priority main important crops.

This brings about that wheat and fababean were the main productive crops for households in the study area. As a result, the production of wheat and fababean is described in this pilot study, as the two crops were the major crops that households in the study area produce in addition to their relative significance in household consumption supplies.

Wheat production: Arsi zone is one of the major wheat producing areas in Ethiopia that accounts for about 63 percent of the national production (Getachew 2001:50). The study area is located in one of the beast wheat producing district in Arsi zone due to the suitability of its topography for mechanization, adoption of improved agricultural inputs, and it's this crop favorable ecology for production of this crop. All household-heads were growing wheat and allocating 1.6 hectares of land to its production (Getachew 2001:50). Table 2 indicates the distribution of household-heads by farms size owed to wheat. 
Table 3: Distribution of household-heads by farms size of wheat field $(\mathrm{no}=\mathbf{2 6})$

\begin{tabular}{|lccl|}
\hline & Household-heads & Percent & $\begin{array}{l}\text { Productive } \\
\text { efficiency rank }\end{array}$ \\
\hline $\begin{array}{l}\text { Farms size category } \\
\text { (Hectares) }\end{array}$ & Number & 19.23 & 3 \\
\hline $\mathbf{1 . 0}$ & 5 & 38.46 & 1 \\
\hline $\mathbf{1 . 5}-\mathbf{2 . 5}$ & 10 & 23.08 & 2 \\
\hline $\mathbf{3 . 0}-\mathbf{4 . 5}$ & 6 & 11.54 & 4 \\
\hline $\mathbf{5 . 0 - 7 . 0}$ & 3 & 07.69 & 5 \\
\hline $\mathbf{2 0 - 2 4}$ & 2 & 100 & \\
\hline Total & 26 & 20 & \\
\hline
\end{tabular}

Source: computed from primary data of (Anbessie survey data 2015)

The stake of wheat farms from total area of land allocated to crops was 12 percent at national level, 17 percent for Oromiya region, and 81 percent for the study area. This shows that the importance of wheat production in the income of households and the tendency towards mono cropping in this area (Getachew 2001:50). Wheat production accounts for about 80 percent of the total cereals and legumes produced by the household-heads. Table 3 describes distribution of household-heads by the amount of wheat production efficiency they produced in the year 2014 (Anbessie 2015).

Table 4: Distribution of household-heads by wheat yield efficiency $(n=26)$

\begin{tabular}{|llllll|}
\hline \multicolumn{7}{|c|}{ Household-Heads by Bread Wheat Yield } \\
\hline $\begin{array}{l}\text { Wheat } \\
\text { Yield(kg) }\end{array}$ & $\begin{array}{l}\text { Wheat } \\
\text { (Quintals) }\end{array}$ & $\begin{array}{l}\text { Yield } \\
\text { Average } \\
\text { Yield(kg) }\end{array}$ & Number & Percent & $\begin{array}{l}\text { Productive } \\
\text { efficiency rank }\end{array}$ \\
\hline $3200-3500$ & $32-35$ & 3375 & 2 & 7.69 & 4 \\
\hline $4000-4800$ & $40-48$ & 4242 & 12 & 46.15 & 3 \\
\hline $5000-5500$ & $50-55$ & 5125 & 8 & 30.77 & 2 \\
\hline $6000-6500$ & $60-65$ & 6125 & 4 & 15.39 & 1 \\
\hline Total & & & & $\mathbf{1 0 0}$ & \\
\hline
\end{tabular}

Source: computed from primary data of (Anbessie Survey Data 2015)

Table 5: Distribution of household-heads by age of groups. (n=26)

\begin{tabular}{|llll|}
\hline Age groups & Number & Percent & Productive efficiency rank \\
\hline $\mathbf{3 2 - 4 5}$ & 11 & 42.31 & 1 \\
\hline $\mathbf{4 6 - 5 5}$ & 10 & 38.46 & 2 \\
\hline $\mathbf{5 6 - 7 2}$ & 05 & 19.23 & 3 \\
\hline Total & 26 & 100 & \\
\hline
\end{tabular}

Source: computed from primary data of (Anbessie Survey Data 2015)

The age distribution of household-heads shows that approximately all the target age groups that should be incorporated in the observation for household's productive efficiency were accommodated. Household heads in the younger age group of 32-45 years belong to those households established after the 1975 land distribution and were suffering from the problem of landlessness. The older people are those who have shown to be of having the problem of agricultural labor due to their powerlessness to work on their farm.

Table 6: Distribution of Households by the level of education $(n=26)$

\begin{tabular}{|c|c|c|c|c|c|c|c|}
\hline \multirow[b]{2}{*}{ Education } & \multicolumn{6}{|c|}{ Level of Education } & \multirow[b]{2}{*}{ Total } \\
\hline & $\begin{array}{l}\text { Number of } \\
\text { Illiterate } \\
\text { Farmers }\end{array}$ & $\begin{array}{l}\text { Number } \\
\text { primary } \\
\text { Farmers } \\
\end{array}$ & $\begin{array}{r}\text { of } \\
\text { school }\end{array}$ & $\begin{array}{l}\text { Number } \\
\text { secondary } \\
\text { Farmers } \\
\end{array}$ & $\begin{array}{r}\text { of } \\
\text { school }\end{array}$ & $\begin{array}{l}\text { Number of } \\
\text { post-secondary } \\
\text { school farmers }\end{array}$ & \\
\hline $\mathbf{0}$ & 4 & & & & & & 4 \\
\hline $1-8$ & & 16 & & & & & 16 \\
\hline $9-12$ & & & & 4 & & & 4 \\
\hline $12^{+1}-12^{+2}$ & & & & & & 2 & 2 \\
\hline Total & 4 & 16 & & 4 & & 2 & 26 \\
\hline
\end{tabular}

Source: Calculated from survey data of (Anbessie 2015)

Level of education is expected to positively contribute to the agricultural productivity of households by increasing their rate of adoption of new agricultural technologies. It is quite apparent that education has a positive contribution in improving the level of productivity of the farmer in all cases. Average crop yield was highest for illiterate mentioned for the relationship between education levels of and farms size. The level of 
household-heads education ranged from illiterate to secondary school and post-secondary education. Most of about 15.38 percent household-heads were not able to read and write. The rest of the household-heads have different levels of education: 15.4 percent attended secondary school education, 61.53 percent attended primary school education, and the remaining 7.69 percent attended postsecondary education. With respect to the gender dimension of educational achievement, female household-heads represent only about 25 percent of the literate group.

The productive efficiency level for the households in Oda Jila, Gonde Finchama, Hatte Handode and Shaki Sherera were 5550, 3892, 4475 and $5250 \mathrm{~kg} / \mathrm{ha}$ respectively and hence; the households in Oda Jila were in the highest production efficiency level compared to all the other surrounding Kebeles of Hetosa district.

\section{The Secondary Data Analysis}

Based on the collected secondary data, it has been attempted to examine the bread wheat productive efficiency of the medium-scale farmers which are with 1-25 hectares of farm sizes in the study area. The analysis has been organized under four parts. The first part describes the relationships between farms size and use of improved agricultural Inputs. The second part investigates distribution of the household-heads by amount of fertilizer used for production. The third part reviews the distribution of households by the No of Extension Contacts (EC) in a year 2001.The last part compares the farms size, households size and average grain productivity level/ha for wheat with average productivity level/ha based on the secondary data of the national, regional, zonal and district levels.

Usage of improved agricultural inputs and technologies: Farmers in the study area have long years of experience in using improved farm inputs like improved seeds, fertilizer, herbicides and pesticides more often for pulse crops. These inputs have been supplying by different private agencies and reach the farm households mainly through MoA and Service Cooperators. These two government organizations take the mandate of competing bids by different supplying agencies and distribute it to farmers.

Table 7: The Relationships between Farms Size and Use of Improved Agricultural Inputs (n=62)

\begin{tabular}{|c|c|c|c|}
\hline \multicolumn{4}{|c|}{ Household-heads } \\
\hline & Farm Size & (ha) & \\
\hline $\begin{array}{l}\text { Used Improved } \\
\text { Agricultural Inputs }\end{array}$ & $\begin{array}{l}\text { Number }(\%) \\
0.1-1.99\end{array}$ & $\begin{array}{l}\text { Number }(\%) \\
2.0-3.5\end{array}$ & $\begin{array}{l}\text { Total } \\
\text { Number }(\%)\end{array}$ \\
\hline No & 23(88.5) & 23(63.9) & 46(74.2) \\
\hline Yes & $03(11.5)$ & 13(36.1) & $16(25.8)$ \\
\hline Total & $26(100)$ & $36(100)$ & $62(100)$ \\
\hline
\end{tabular}

Source: Computed from Survey Data of (Anbessie 2007)

As indicated on Table 6 the relationship between farms size and improved farm technologies utilization was significant. A relatively higher proportion of households that owned larger farms size than those with smaller farms size used improved farm inputs. Fertilizers are one of the important chemical inputs used in crop production. Table 7 indicates distribution of household-heads by the amount of fertilizer used for crop production.

Table 8: Distribution of household-heads by amount of fertilizer used for production $(\mathbf{n}=55)$

\begin{tabular}{|llll|}
\hline & Household-heads & Rank \\
\hline Amount of fertilizer & Number & Percent & 2 \\
\hline $0.10-0.75$ & 9 & 16.4 & 1 \\
\hline $1.00-3.00$ & 41 & 74.5 & 3 \\
\hline $4.00-40.00$ & 5 & 09.1 & \\
\hline Total & 55 & 100 & \\
\hline
\end{tabular}

Source: computed from survey data of (Getachew 2001:54)

Studies on fertilizer use showed that farms size, household income, price of fertilizer in relation to crop price, credit and market access were the principal socio-economic factors affecting stallholders demand. Even though the experience and interest of most of the household-heads in using improved seeds, only about 31 percent of the household-heads were found to use improved seeds of wheat and barley and each of these household-heads purchased about 136kgs in the late 2006s. On the other hand, about 49 percent of the household-heads had problem of seed shortage. 
Table 9: Distribution of Households by the No of EC in a year 2001(n=31)

\begin{tabular}{|llll|}
\hline \multicolumn{4}{c|}{ Household-heads Extension Contact (EC) } \\
\hline $\begin{array}{l}\text { Total days of EC } \\
\text { In a year }\end{array}$ & Number & Percent & Rank \\
\hline $1-3$ & 12 & 38.7 & 1 \\
\hline $4-36$ & 8 & 25.8 & 3 \\
\hline Every time & 11 & 35.5 & 2 \\
\hline Total & 31 & 100 & \\
\hline
\end{tabular}

Source: Adopted from survey data of (Getachew 2001)

On account of the fact that it is so easy to observe from Table 8 that, a most related study done in the previous year on food security situation by (Getachew 2001:58) proved that 35.5 percent of the household-heads meet with DAs almost every day which on the average about 64.5 percent of the household-heads meet with DAs about 5 days in year. Several of household-heads participated in Extension Package program was even much less than those who had contact with extension DAs. The package program was targeted to provide the farmer with the necessary inputs on credit basis provided that they will use the recommended rats of each input and work as per the advises of the agent.

Table 10: The Relationship between the farmers' level of education and total farms size (n=77)

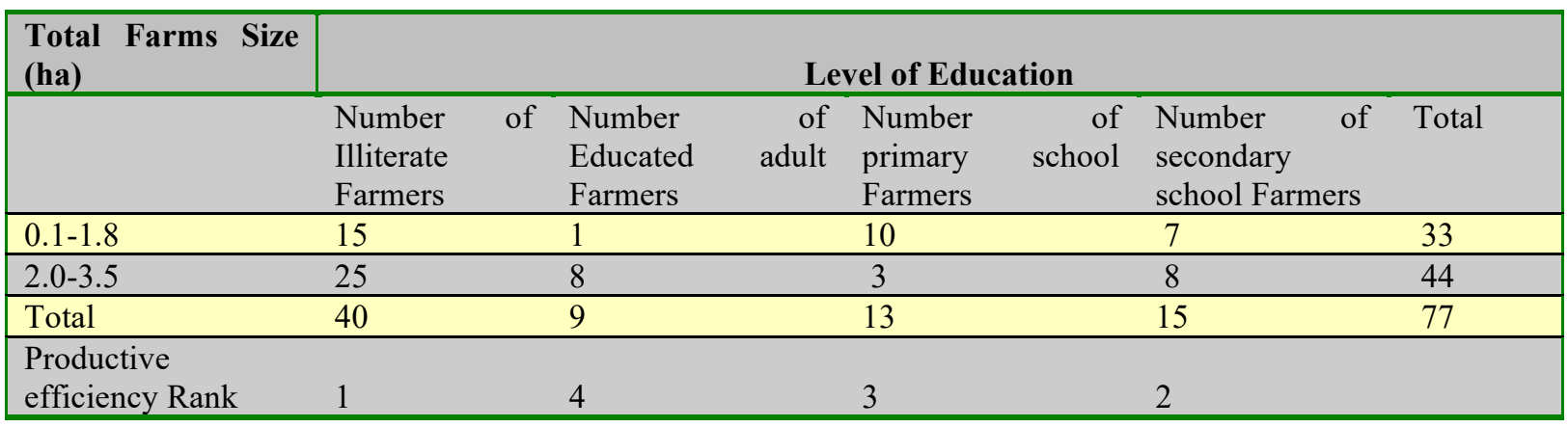

Source: Calculated from survey data of (Anbessie 2007)

These data was collected in the late 2007s from the study area. The subsequently study shows that the higher production of educated farmers owned smaller farms size than the illiterate farmers. It is evident that there seems to be two reasons which could be of familiar to this end. Either the better-educated rural people were more interested in gating government employment somewhere outside their community than to work on the form or they might have been under 18 and attending school by the time of land distribution in 1970s. Level of education is expected to positively contribute to the agricultural productivity of households by increasing their rate of adoption of new agricultural technologies. Contrary to this fact, a significant negative relationship was found between levels of education of household-heads and crop productivity in the study area. However, this does not mean that education has negatively contributed to development in the area. The reverse interaction was rather due to the difference in resource endowment between the illiterate and literate household-heads.

It is quite apparent that education has a positive contribution in improving the level of productivity of the farmer in all cases. Average crop yield was highest for illiterate mentioned for the relationship between education levels of and farms size. The level of household-heads education ranged from illiterate to secondary school and post-secondary education. Most of about 52.3 percent household-heads were not able to read and write. The rest of the household-heads have different levels of education: 20 percent attended secondary school education, 15.4 percent attended primary school education, and the remaining 12.3 percent attended adult education. With respect to the gender dimension of educational achievement, female household-heads represent only about 18.9 percent of the literate group.

\footnotetext{
${ }^{1}$ More than 50 percent of the household-heads did not have contact with extension agents.
} 
Table 11: Comparison of selected farms size, households' size and average grain productivity level ha ${ }^{1}$ for wheat with average productivity level/ha data of the national, regional, zonal and district levels.

\begin{tabular}{|c|c|c|c|c|c|}
\hline $\begin{array}{lll}\text { Households } & \& & \text { Farms } \\
\text { Characteristics } & & \end{array}$ & Study Area & $\begin{array}{l}\text { Hetosa } \\
\text { district }\end{array}$ & Arsi zone & $\begin{array}{l}\text { Oromiya } \\
\text { Region }\end{array}$ & $\begin{array}{l}\text { National } \\
\text { Level }\end{array}$ \\
\hline $\begin{array}{l}\text { Average numbers of households } \\
\text { size }\end{array}$ & 7.00 & 5.25 & 5.00 & 5.40 & 5.12 \\
\hline $\begin{array}{l}\text { Average farms size in household- } \\
\text { heads }\end{array}$ & 1.92 & 1.70 & 1.48 & 1.21 & 1.02 \\
\hline \multicolumn{6}{|l|}{ Crops productivity in KG/ha } \\
\hline Wheat & 23.70 & 23.52 & 15.47 & 15.41 & 13.79 \\
\hline
\end{tabular}

Source: Adopted from survey data of (Getachew 2001:72)

Table 12: Average productivity comparison of selected farms size, households' size for wheat with the data of world wide, national, regional, zonal and district levels.

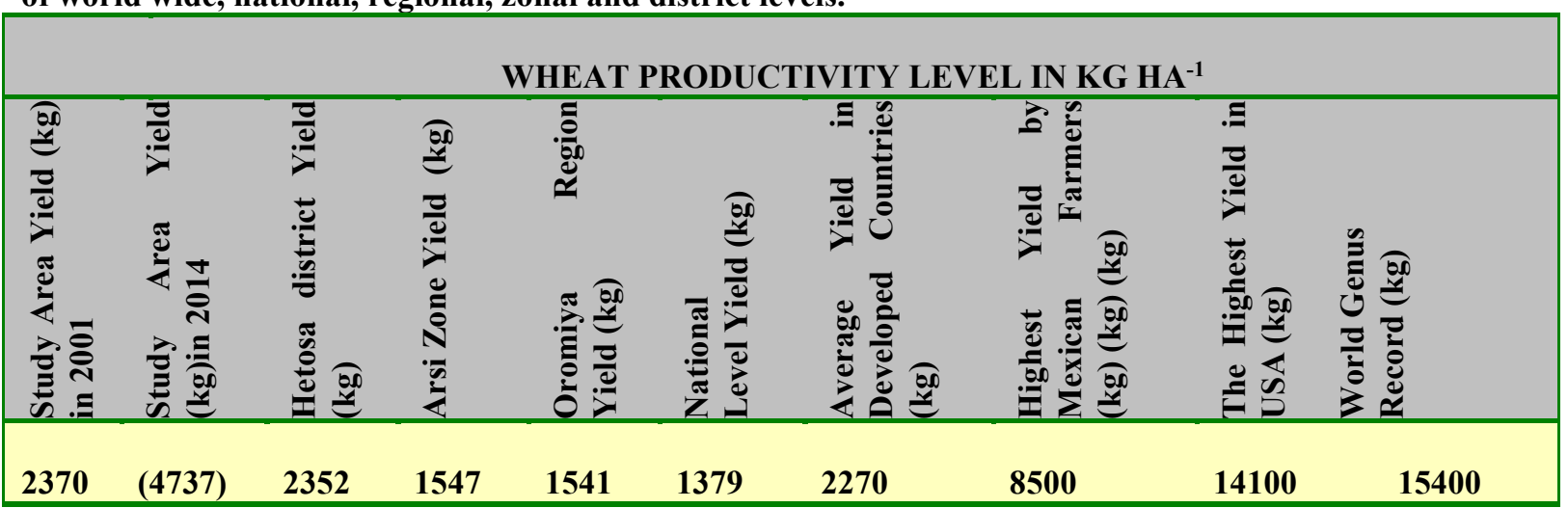

Source: Calculated from survey data of (Anbessie 2015, Getachew 2001) and (Borlaug et al., 1982)

Average farmers size and household in the study area were higher than that of national, regional and zonal averages; wheat and barley productivity levels/ha was the highest in the study area compared to the national, regional and zonal averages. It was also a bit higher than the average productivity per hectare for Hetosa district. This shows that the higher crop production potential of the area even amongst the other PA kebeles in this district. The average wheat productivity per household-head in the study area was $2600 \mathrm{~kg}$ which is 26 quintals. However, more than 50 percent of the household-heads produced less than the average.

The average productivity per hectare of wheat was $2300 \mathrm{~kg}$ or 23 quintals for the study area, it was higher than both national averages of 14 quintals per hectare, and zonal average for Arsi was 16 in the same year.

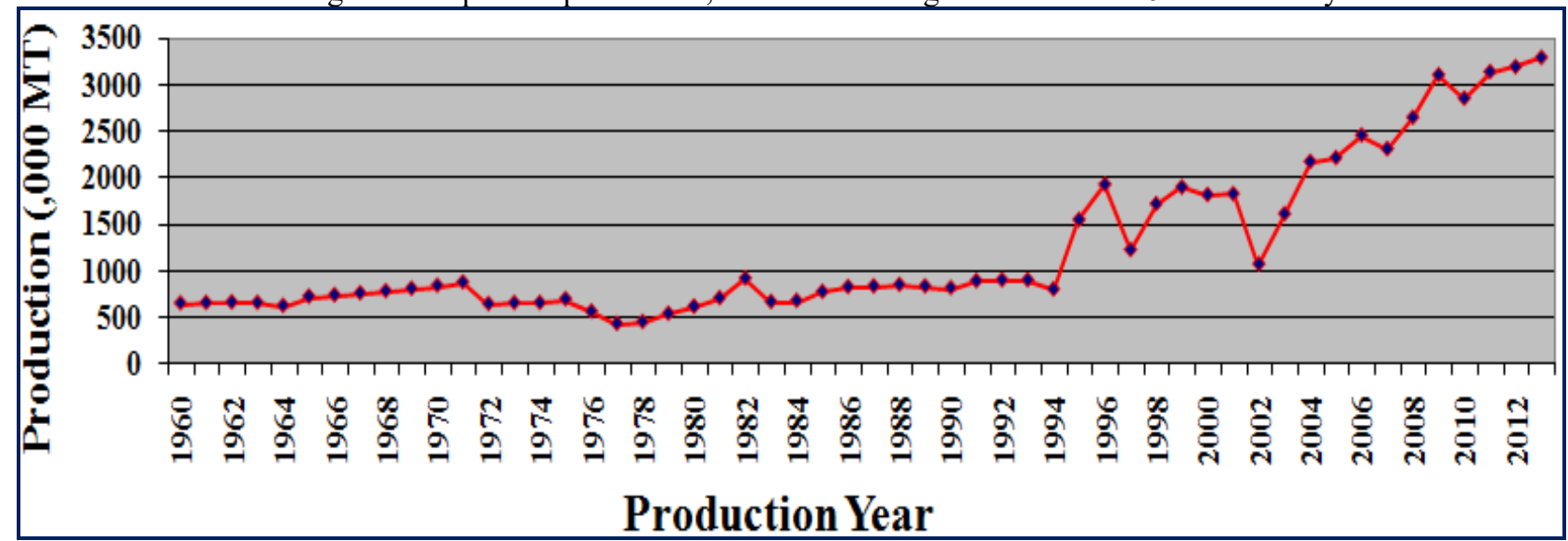

Figure 11: The national average yield productivity from the year 1960 - 2012 GC

Source: USDA, http://www.indexmundi.com/agriculture/

This figure will indicate us the national average yield productivity must need to be increased by genetic improvement and fertilizer application. Bread-wheat is believed to be a relatively recent introduction to Ethiopia (Hailu, 1991); it exhibits wider adaptation and higher yield potential than durum wheat (Amsal, 2001). Drought prone environments particularly semi-arid environments, which cover $50 \%$ of the country's arable land area, have been one of the principal constraints for wheat production in rainfed areas. 


\section{CONCLUSION AND RECOMMENDATION}

The principal arguments of this pilot study can be presented as follows. The purpose of this chapter is to summarize the results of this pilot study and draw conclusions and charts out a somewhat considerable recommendation based on the initially designed objectives of the study The recommendations suggested are primarily addressed to the households residing in the four kebeles s of Hetosa District, which is officially known under, their kebeles name of Oda Jila, Gonde Finchama, Hatte Handode and Shaki Sherera, that are the focus of this pilot study in particular and Hetosa district of Arsi zone.

\subsection{Conclusion}

In view of the fact that the average household amount and farms size in the study area were higher than that of national, regional, and zonal averages. However, a significant proportion of households had the problem of farmland shortage. The mechanism some of these households used to increase their farms size holding, particularly reclaiming marginal lands was an ecologically divesting action that increases vulnerability of households for the unproductively situations.

- Farming was the main source of lively hood for the majority of the households in the study area. Most of the households did not have any off-farm income source. As the dominant farming activity, in the study area was rain fed crop production activity and hence these households are at risk of facing the problem of unproductively every years.

- Households with smaller farms size are normally expected to intensify their farming activity using more improved farm inputs than households with larger farms size. However, farms size directly related to input utilization in this spilt study. This could be of the effects of the minimum farms a size criterion for participating in extension package program that excluded households that did not have 1 hectare of land in one plot from participating in the program.

- Level of education is expected to positively contribute to the agricultural productivity of households by increasing their rate of adoption of new agricultural technologies. Contrary to this fact, a significant negative relationship was found between levels of education of household-heads and crop productivity in the study area. However, this does not mean that education has negatively contributed to development in the area. The reverse relationship was rather due to the difference in resource endowment between the illiterate and literate household-heads.

- The most important crops produced in the study area were wheat and fababean with the former accounting for 80.1 percent of the total crops produced in the area and covering 81 percent of the area allocated to cereals and pulses. A considerable proportion of household-heads have reduced the amount of fertilizer and improved seed they used particularly due to unaffordable high prices.

- Close to typical, households in the study area were productive. However, further analysis of the local situation revealed that significant proportion of households in the area were unproductive; and there was high inequality between locations and households in their level of productive efficiency.

- The low level of productivity in the study area is an indication of the existing of substantial potential to improve the households' productivity with minimum cost compared to the development and introduction of new technology.

\subsection{Recommendation}

- One of the pilot principles that households used to increase their farms size, reclaiming marginal lands, is an ecologically devastating measure. Thus, the extension system should strengthen its activity in the intensification of farming. In order to achieve intensification, two important measures are recommended. The first measure is to abandon the minimum farms size principle that excluded farmers with small farms size from participation in the package program.

- The next recommended measure is to commence adult education program that can continuously raise farmer's understanding about their ecology and intensive agricultural practices.

- The anxiety and abuse of credit in the study area calls for education in its utilization. Rural households shall get advisory services in credit utilization and saving. Thus, it is essentially to build the capacity of extension agents in line with this issue.

- The propensity of households towards of mono coping with wheat in the study area earns special attention from the research and extension system in the area. The extension system should encourage diversification than concentrating on wheat.

This could be achieved through provision of improved varieties of high yielding alternative crops, particularly pulses with their full package of agronomic practices.

- The sudden reduction in and raise of grain price was another issue that needs substantial attention by the concerned bodies. With regard to this, the government should be capable of stabilize the grain market.

- Average household size in the study area was higher than the national average. With present rate of population 
growth, this would be aggravating the problem of farmland and natural resource degradation in the area. Thus, intensive family planning and population education is tremendously essential in the study area.

- Given the limited resources the government may fare better if it works to wards of improving the agricultural productivity level of the farmers in the study area to be cost effective.

- Thus, from now to onwards, depending on the availability of resources, both ways of raising the small farms size productivity have to be followed although priority ought to be given to the improvement of farmers' productivity.

- Efficient farmers need to be provided with more cropping farm lands which in such a way to increase the agricultural productivity in the study area.

\section{REFERENCE}

A bate, B. (1995), 'On-farm Analysis of Improved Production Technology for Durum Wheat' Proceeding of the Ninth Regional Wheat Workshop for Eastern Central and Southern Africa, CIMMYT, Addis Ababa, Ethiopia. PP. 226-230.

Anbessie Debebe, (2015). Pilot Assessment on the Small Scale Farms Agricultural Productivity: A Review Paper for senior seminar submitted to the Department of Plant Science, Collage of Agriculture and Environmental Science, Adama Science and Technology University, in Partial Fulfillment of the Requirement for the Degree of BSc in Plant Science, Adama, Ethiopia

Anbessie Debebe, (2007). Pilot Study on the Household-Oriented Peasants Farm Land Size and Agricultural Productivity Situations in Selected Farmer Kebeles of Hetosa Woreda in Arsi Zone; A Senior Research Project Paper Submitted to the Department of Economics, School of Business and Economics, Unity University, In Partial Fulfillment of the Requirements for the Degree of BA in Economics, Addis Ababa, Ethiopia.

Borloug, et. al. (1982), Wheat in the third world, West view press, Boulder, Colorado, USA.

CIMMYT (1988), An Economic Training Manual: From Agronomic Data to Farmer Recommendations, Economics program, Mexico, DF, Mexico.

CSA, 2002. Agricultural sample survey: Report on area and production of major crops. Addis Ababa, Ethiopia.

Getachew, L. (2001), A Study of Household Food Security Situation of Farm Households in Selected Peasant Associations of Hetosa, Arsi Zone, Ethiopia. MSc Theses, University College of Dublin, UK.

Hailu, G. (1991), "Wheat Research in Ethiopia", (Eds), In, Tanner D.G.and Mengistu H., A Historical Perspective, IAR/CIIMMYT, Addis Ababa, Ethiopia.

Mohammed, H. (1999), Smallholders' Crop Production Efficiency: The Case of Asasa Plain in Arsi. MSc Theses, School of Graduate studies, Alemaya University of Agriculture Dire Dawa, Ethiopia.

USDA http://www.indexmundi.com/agriculture/

Yesuf, A. and Duga, D. (2000), 'Economic Analysis of N Fertilizer Use on Bread Wheat', Ethiopian Journal of Natural Resource, vol. 2 No 1pp.93-1 